\title{
SISTEMA PRODUCTIVO DE LA COMUNIDAD INDIGENA MISKITU DE TASBARRAYA, RAAN
}

Enrique Cordón Suárez ${ }^{[1]}$

\section{Resumen}

Se analizaron los sistemas productivos de la comunidad indígena miskitu de Tasbarraya en la RAAN, con el fin de valorar su riqueza y diversidad, y promover los sistemas productivos sostenibles. Se realizaron dos talleres con los comunitarios para conocer la lógica de los sistemas productivos que practican y razón de su sobrevivencia en el tiempo. De igual manera se complementó con la visita a tres fincas agropecuarias para su descripción espacial y caracterización de los cultivos y método de manejo.

Entre los principales resultados se obtuvo que los sistemas productivos indígenas utilizan el sistema de roza, tumba y quema; sin embargo, utilizan un barbecho prolongado del suelo. El sistema productivo practica un sistema de barbecho largo que dura de 5-10 años o más, esto permite la recuperación del bosque desde el proceso de sucesión primaria hasta la conformación de un bosque secundario.

La modalidad de rotación de parcelas, contribuye por sí misma a la recuperación de los suelos, y de la vegetación, siempre y cuando la tierra se deje descansar por largos períodos de tiempo. Sin embargo, en algunos casos los indígenas miskitus se han visto obligados a reducir la duración del barbecho antes de la reutilización de las parcelas hasta 5 años o menos a causa de la presión demográfica, y lucha por la tenencia de la tierra entre las comunidades vecinas. Esto afecta sus prácticas agrícolas tradicionales y podría también poner en cuestionamiento la estabilidad del ecosistema.

Palabras clave: Sistemas productivos, barbecho prolongado, rotación de parcelas.

\section{Summary}

The production systems of the miskitu indigenous community of Tasba Raya, RAAN, were analyzed in order to estimate its richness and diversity, and promote the sustainable production systems. Two workshops were carried out with the community to know the logic of the production systems they practice as well as to determine how it survives over time. Likewise, this study was complemented with visits to three agricultural farms for spatial description, characterization of crops and management method.

[1] PhD. Enrique Cordón Suarez, docente e investigador de la URACCAN BILWI. encordon@yahoo.com 
Among the main results that were obtained, we can mention that indigenous production systems use the slash and burn system; however, they also use a long fallow land. The production system practice a long fallow land system that lasts for 5-10 years or more, this allows the forest recovery from the process of primary succession until the conformation of a secondary forest.

The plots rotation modality, contributes to the recovery of soils and vegetation, as long as the land is left to rest for long periods of time. However, in some cases the Miskitus indigenous have been forced to reduce the fallow lifespan before reusing the plots up to 5 years or less due to demographic pressure, and the struggle for land ownership between neighboring communities. This situation affects their traditional agricultural practices and could also put into question the stability of the ecosystem.

Keywords: Production systems, long fallow land, plots rotation.

\section{Introducción}

La comunidad indígena de Tasbarraya se encuentra en su mayoría asentada en el municipio de Waspam, conformado por 1800 habitantes aproximadamente. Según el censo poblacional del año 2007, goza de una riqueza cultural que abarca diferentes ámbitos como la lengua, la curación con plantas medicinales, su gastronomía, y de alguna manera todas estas expresiones están íntimamente relacionadas con su territorio ancestral y también con su espacio aledaño a la vivienda donde aparte de habitar, cultivan sus alimentos y medicinas; plantan árboles para la construcción de viviendas y donde crían animales domésticos.

Este lugar llamado Insla en su lengua miskitu, posee una diversidad florística donde los alimentos juegan un papel muy importante dentro de esta amplia gama, al igual que las especies medicinales y forestales. Comparte el legado de sus antepasados, desarrollan allí su vida, mantienen y generan conocimientos en variados ámbitos y modelan su existencia de acuerdo a sus necesidades y oportunidades que les brinda su entorno, por lo tanto su sistema de vida y productivo esta íntimamente ligado a su supervivencia ancestral.

Se ve la necesidad de llevar a cabo esta investigación puesto que el sistema productivo casero es una fuente importante de alimentos para el comunitario, existe una gran biodiversidad de tubérculos, frutas y verduras que generan gran parte de la seguridad alimentaria a la familia que aún conserva el huerto casero o Insla como sistema productivo, además también aporta medicinas y combustible a la familia. Algunos de los excedentes de la producción generan entradas económicas y en otros casos sirven de medio de transacción con otros productos y servicios a nivel regional. 


\section{CULTURA INDÍGENA Y AFRODESCENDIENTE}

La presente investigación tiene como objetivo analizar el sistema productivo de la comunidad indígena miskitu de Tasbarraya, RAAN, con el fin de valorar su riqueza y diversidad, y promover los sistemas productivos sostenibles.

\section{Marco referencial}

\section{El sistema de producción}

El término "sistema" se entiende como el arreglo o conjunto de componentes, unidos o relacionados de tal manera que forman parte de un todo (Hart, 1980), y el de "producción" como la generación de bienes a través del uso de trabajo, equipos y materiales. Entonces una aproximación al concepto de "sistemas de producción" es el conjunto de elementos organizados funcional y estructuralmente para generar bienes y servicios al ser humano a partir de los recursos naturales.

La transformación de los sistemas naturales hacia sistemas intervenidos por el hombre para su beneficio, con la producción de alimentos, animales y plantaciones de árboles es lo que se conoce como agro ecosistemas (Harmon y Sutton, 1977).

Los agro ecosistemas se pueden clasificar en sistemas agropecuarios, agrícolas, pecuarios, forestales, agroforestales dependiendo de los beneficios que se quieran generar o de la combinación de estos. Para efectos de esta investigación los más relevantes son los agrícolas, pecuarios y agroforestales.

Por otro lado, el IDH $\mathrm{IDH}^{[2]}$, (2005:151), "la economía de las regiones autónomas (Nicaragua) se desarrolla en base a tres modos de producción: La economía campesina, la economía indígena comunitaria y la economía empresarial exportadora de materia prima a nivel primario".

Como la investigación se lleva a cabo dentro de los sistemas de producción Indígena y campesina, entendemos estos sistemas de producción tradicional tal como lo plantea Levard y es retomado por Nitlapan en su cuaderno de investigación No. 33 (NITLAPAN, 2010:21).

Un sistema de producción en un ecosistema, es el resultado de la combinación a través del tiempo de los factores como las fuerzas de trabajo y medios de producción, bajo la dirección de un centro de decisión.

De este modo, considero que estos tres elementos pueden tener características distintivas entre un sistema de producción campesina $(\mathrm{SPC})^{[3]}$ y un sistema de producción

[2] Índice de Desarrollo Humano.

[3] Sistema de producción tradicional campesina . 
indígena (SPI) ${ }^{[4]}$ tomando en cuenta que la racionalidad u objetivo de producción difieren en ambos casos. Estos sistemas diferentes se describen seguidamente.

\section{Sistema de producción tradicional indígena (SPI)}

Es importante destacar que el sistema de producción indígena tiene como característica básica el sustento básico de la familia, principalmente, con visión de uso cultural y espiritual, en pro de la identidad de un conglomerado de pobladores.

Los sistemas agrícolas dentro de los SPI combinan varias actividades bajo un plan de economía de gestión comunal de recursos naturales. Por lo tanto "la sostenibilidad y el crecimiento pueden estar determinados por las extensiones de las áreas de cultivos, por la diversidad de la producción y por las necesidades del consumo" (NITLAPAN, 2010).

En otras palabras, los SPI es el ejercicio de vida social de un pueblo en un ecosistema dado con visión de construir su futuro y poniendo en práctica las enseñanzas ancestrales e históricas de uso y conservación de los recursos naturales y potenciales. En este sentido los bosques atesoran el mundo cosmológico de los habitantes nativos, por ello todo el bosque es la vida de la comunidad indígena, en el sentido material, espiritual y cultural. Esto conlleva a la sostenibilidad de los ecosistemas en el tiempo.

Por otro lado, en el modelo productivo indígena, contrario al modelo campesino, se ubican las sociedades que tienen como característica fundamental las relaciones entre individuos y familias, su sistema organizativo se rigen por las relaciones de parentesco (reglas de distribución, reciprocidad, redistribución); los cargos no son hereditarios y el liderazgo se ejerce por consenso y aceptación (o rechazo). Se remarca con lo mencionado por Grünberg (2007:33), "en el sistema de vida indígena no existen clases sociales, pero hay diferencias en prestigio (status), en posiciones y en habilidades".

Por tanto los sistemas ecológicos indígenas configuran diferentes espacios de ocupación que incluyen áreas de conservación, reservas de vida silvestre y bosques agrícolas. Todo esto se asemeja a un sistema agroecológico indígena, buscando el equilibrio biodinámica de la vida y de los beneficios en forma colectiva.

\section{Deforestación y comunidades indígenas}

La actividad principal de las comunidades indígenas en la Costa Caribe nicaragüense es la agricultura de parcelas rotativas y está normalmente restringida por los suelos asociados a los latifoliadas y los bosques ribereños.

[4] Sistema de producción tradicional Indígena. 
Los comunitarios miskitus utilizan aproximadamente de 1-3 hectárea por familia y a ésta área se le llama en lengua miskitu "insla", que significa huerto o parcela agrícola. Se cultiva por un lapso de 2 a 4 años, con arroz, frijoles, musáceas, raíces, tubérculos y otros cultivos de manera dispersa en el área, pero bajo la lógica indígena tienen un orden natural del cultivo, a lo que podríamos llamarlo técnicamente una asociación de cultivos.

Luego esta área es abandonada por un período de 5-8 años y se desarrolla el barbecho. Estos barbechos pueden seguir un ciclo de rotación de parcelas y pueden ser reutilizados para los mismos fines agrícolas o ser abandonados definitivamente para que continúen el proceso de sucesión hacia un bosque secundario.

Es de mencionar que las comunidades indígenas no viven exclusivamente de las actividades agrícolas como los campesinos y su fin no es de comercialización de su producción, sino que hacen un aprovechamiento más integral del bosque, (flora y fauna), con una visión que no pone en riesgo el ecosistema.

\section{Diseño metodológico}

\section{La comunidad indígena de Tasbarraya}

La comunidad de Tasbarraya se funda a finales de la década del 60 e inicios del 70 del siglo pasado. Su población es de la etnia miskitu, que vinieron bajo un plan de reubicación voluntaria de comunidades indígenas del Río Coco abajo. Eran comunidades expuestas a altos riesgos de inundaciones, enfermedades, escasez de tierras agrícolas y conflictos limítrofes entre Honduras y Nicaragua provocados por la guerra de Mocorón en1958 y el fallo de la Haya (1960). Durante este fallo parte del territorio Nacional fue cedido a Honduras (Mosquitia).

El territorio, por sus características hidrológicas y edafológicas, comprende un ambiente de bosque tropical lluvioso y humero de pluvio selva, con formaciones básicas de Bosque de coníferas, constituido por Pino caribeño y asociación de palmeras. También de bosque latifoliados se caracteriza por una alta diversidad de especies, un alto interés comercial y ecológica que comprende un conjunto de habitad, para una variedad de especies de fauna.

Se estima que el bosque productivo latifoliados tiene una densidad de 420 árboles por hectárea para una producción de 90 metros cúbicos. Aunque una buena porción de estos ecosistemas ya han sido aprovechados y tienen más bien potencial ecológico y para ser considerado como áreas de conservación.

Entre las especies de árboles comerciales de mayor importancia para la comunidad, podemos mencionar: Caoba (Swietenia macro philla), Cedro Real (Cedrela odorata), 
Granadillo (Dalbergia tucurencis), Laurel (Cordia alliodora), Santa María (Callophillum brasiliense), Cedro macho (Carapa guinenese), Maria (Calophilum brasilensis), Kerosén (Tetragastris panamensis), Leche maría (Symponia globulifera), Quita calzón (Astronium graveolens), Guapinol (Himenaea courbaril L), Mora (Chlorophora tinectoria), Níspero (Manilkara zapota), Nancitón (Hyeronima alchorneoides), entre otras especies. Estas especies son representativas en todo el bosque del municipio de Waspam.

La principal fuente económica de la comunidad de Tasbarraya es la agricultura de subsistencia familiar con el cultivo de arroz, frijoles, musáceas, tubérculos y yuca, principalmente. Es considerada una agricultura de subsistencia debido a que la producción local es destinada para el autoconsumo ( $85 \%$ ) y su excedente es comercializada o intercambiada en los mercados de los municipios de Waspam y Puerto Cabezas. No obstante presentan grandes dificultades para el traslado de la producción, por la falta de trasporte, las frecuentes lluvias y los malos caminos.

Según cálculos recopilados durante el proceso del diagnóstico territorial (CONADETI, 2008:42), la producción total y anual de arroz asciende a 14,500 quintales en granza, los cuales son procesados rústicamente en piladores confeccionados a base de madera, en el que se estima que el rendimiento del grano entero es de aproximadamente 50-60\%, mientras que el de las trilladoras es superior al 70\%, según la calidad del trillo y grado de manejo post cosecha. En este mismo orden, se estima que la cosecha de frijoles es de aproximadamente 8,400 quintales, mientras que el de Maíz alcanza los 2,100 quintales.

Es importante destacar que Tasbarraya es una comunidad agrícola, la producción de granos básicos, musáceas y yuca, es significativa y es de gran valor de uso y consumo local, ya que constituye su alimentación básica del año. Lo poco que se vende (15-20\%) es para adquirir productos que no pueden obtener del bosque. Por ejemplo la sal, el jabón, aceite, herramientas de trabajo (machete, hachas, limas, botas), entre otros.

\section{Tipo de estudio y variables}

Es una investigación cualitativa de corte transversal, ya que la investigación busca recopilar la tradición de uso del suelo, a través de los sistemas productivos.

El proceso de recolección de la información se hizo mediante visitas al campo para la aplicación de las entrevistas tanto a comunitarios productores individuales como a grupos focales. Se utilizaron las técnicas de entrevistas abiertas y observaciones directas.

Para el desarrollo del estudio se definieron las siguientes variables: El cambio de uso del suelo y la degradación del bosque, las practicas de producción tradicional y los factores de cambios socio ambiental presentes en las áreas de estudio. 


\section{Universo y muestra del estudio}

La definición y selección de comunidades se hizo en base a una muestra deliberada tomando en cuenta las experiencias agrícolas, pecuarias, forestales y modalidades de tenencia de la tierra, de tal menara que fueran representativas de todo el municipio de Waspam.

El universo del estudio comprende el área total de ambas comunidades que corresponde a 122,074 hectáreas. Tasbarraya con un área de 109,574 y una población 2450 habitantes distribuidos en 367 familias y la comunidad mestiza de Mosspam con un área de 12,500 hectáreas, y una población de 520 habitantes distribuidos en 55 familias.

Se entrevistó a un total de 65 jefes de familia o productores distribuidos de la siguiente forma: 30 en Mosspam y 35 distribuidos en la comunidad de Tasbarraya. También se hicieron dos grupos focales de 12 miembros para cada grupo étnico. El grupo focal de Mosspam comprendido de 5 líderes y 7 comunitarios. De la misma manera en la comunidad de Tasbarraya 6 líderes y 6 comunitarios. Cabe mencionar que los grupos focales contribuyeron a reforzar la información de campo obtenida por entrevistas y por observaciones.

\section{Resultados y discusión}

\section{El sistema productivo}

En primer lugar se debe señalar que el pueblo miskitu que habita entre bosques húmedos tropicales, como es el caso de la comunidad de Tasbarraya, actúan en forma diferente al sistema de agricultura convencional. Su sistema productivo se caracteriza por el manejo de la rotación de parcelas agrícolas pequeñas, complementadas con la casería, la pesca y la recolección de especies vegetales.

Los miskitus han desarrollado durante muchos siglos un conjunto de conocimientos sobre los ecosistemas y sus elementos a partir de los cuales han diseñado y aplicado una serie de tecnologías y estrategias de producción para su sobrevivencia. Un ejemplo de esto es la siembra y uso de técnicas tradicionales que se integran al conjunto de la vida cultural, tal como es el sistema agrícola de roza, tumba, quema y siembra, luego un barbecho largo. También desarrollan los huertos mixtos a una escala de economía comunal doméstica.

Ellos trabajan lo que llaman la parcela o "insla ${ }^{[5]}$, practican una agricultura itinerante o rotativa. En el caso de la siembra de granos básicos y/o cultivos de ciclos anuales, utilizan el mismo espacio por un período de dos a tres años, para luego cambiar

[5] Nombre en miskitu que se le da a los sitios de siembra. 
y preparar otro sitio, y este se deja en descanso. Este período de descanso según un comunitario es por un tiempo aproximadamente de unos 4 a 7 años y a esto le llaman barbecho viejo (unta almuk). Ahora, según la recuperación del suelo o restauración de la fertilidad, ellos pueden regresan a sembrar el suelo o dejarlo definitivamente para que se convierta en un bosque secundario.

Aquí se reproduce una estructura similar a la de selva natural, se imita un sistema de bosque natural, o sea, orientando al medio original hacia un bosque cosechable de utilidad comunal. Según los comunitarios, estas prácticas son heredadas de los ancestros y ha dado buenos resultados, manteniéndose por generaciones.

Según Morales (2009), "la roza tumba y quema, es una práctica agrícola utilizada en muchas culturas indígenas de los trópicos y les permite su sobrevivencia y convivencia con el medio natural". Los indígenas miskitus no son la excepción, ellos la implementan en un $100 \%$, y forma parte de su sistema de vida tradicional.

\section{Agricultura migratoria}

La agricultura migratoria indígena se desarrolla bajo el siguiente proceso, si el agricultor indígena va sembrar por primera vez en un sitio, lo primero que hace es calcular de manera visual un espacio o área dentro del bosque que el considera puede trabajar y manejar con su familia. Este espacio debe de ser apropiado para los cultivos que pretende establecer y la cantidad. Esta puede ser de 1-3 hectáreas, dependiendo del número de miembros de la familia y la ayuda a mantener el sistema productivo. Generalmente esta actividad comienza a inicios del mes de abril y finaliza en la última semana del mes de mayo con la siembra.

El segundo paso es la socola que consiste en cortar todo el sotobosque y tumbar algunos árboles de mediano diámetro del bosque según el caso. Posteriormente se deja secar al sol la vegetación cortada por un período de 2-3 semanas, seguidamente tumba los arboles grandes con hacha y los deja secar durante otros 20-30 días. Finalmente se hace una sola quema. La quema se hace en un día bien soleado, iniciando entre las 9-10 am y se deja durante todo el día y la noche quemando. Los siguientes días posteriores a la quema solo se supervisa para que el fuego no salga de control. Tres días después de finalizada la quema, se recogen en el centro del área los troncos y ramas mal quemados y se vuelven a quemar.

Esta práctica les permite producir abundantes cenizas que se traducen en nutrientes disponibles para los cultivos en las primeras capas del suelo. En los dos primeros años la parcela produce una buena cosecha, debido a que los cultivos absorben los elementos minerales de los primeros estratos de suelo, sin embargo a partir del tercer año los rendimientos de los cultivos inician a mermar por la carencia de nutrientes 
en el suelo. Gran parte de los nutrientes desaparecen por la absorción de las plantas, por la lixiviación de bases a capas más profundas y lavado por erosión hídrica y eólica.

Por otro lado las malas hierbas agresivas inician a tener control del área agrícola, especialmente las Cyperaceas y las Poaceas (Cyperus rotundus, Cyperus esculentus, Anthephora hermaphrodita, Cechus browni), entre otras, las cuales tienen sistemas radiculares difusos y resistentes, por lo que su eliminación es más difícil y más bien con las labores mecánicas de control se da una mayor diseminación por medio de la partición de su sistema radicular.

Es así que existe el inconveniente de que el suelo sea abandonado por el empobrecimiento nutritivo y queda como barbecho por varios años, que podría ser de 5-8 años. El comunitario continúa abriendo nuevos espacios en el boque hasta su posible regreso al mismo sitio después de un largo período de barbecho.

Considero que este procedimiento (barbecho) es una práctica necesaria para el descanso y recuperación de la tierra, lo mismo que para eliminar enfermedades de los cultivos y plagas de animales. Generalmente son rotaciones de parcelas y de barbechos prolongados, hasta que surge una vegetación nueva.

La modalidad de rotación de parcelas, contribuye por sí mismas a la recuperación de los suelos, y de la vegetación, siempre y cuando la tierra sea dejada a descansar por largos períodos de tiempo. Sin embargo, en algunos casos los indígenas miskitus se han visto obligados a reducir la duración del barbecho antes de la reutilización de las parcelas hasta 5 años o menos a causa de la presión demográfica, y lucha por la tenencia de la tierra con comunidades vecinas. Esto afecta sus prácticas agrícolas tradicionales y podría también poner en cuestionamiento la estabilidad del ecosistema.

\section{El proceso de barbecho prolongado}

Los aspectos más relevantes del proceso de sucesión secundaria en las condiciones de bosque tropical húmedo y las formas agrícolas tradicionales como los de la RAAN, es el siguiente.

En los dos primeros años de abandono de la parcela agrícola, surge una vegetación herbácea perenne, con predominio de las especies Poáceas, otra vegetación enmarañada con arbustos y plántulas de especies invasoras, que sirve de hogar a muchos insectos, cubre el suelo y los restos de troncos de los árboles tumbados. De forma progresiva, cuando la parcela es abandonada se inicia un proceso de reestructuración del bosque que comienza con la total desaparición de vegetales estacionales y el espacio comienza a cubrirse con una diversidad de especies gramíneas y arbustos. 
A los cuatro años se tiene un sistema compuesto por arboles ya formados, ya hay vestigios de vegetación primaria junto a un estrato arbustivo y leñoso compuesto por especies pioneras que crecen en forma espontanea, generalmente de la familia Cecropiaceae.

A partir de los cinco años la composición vertical toma importancia de manera paulatina y el indígena miskitu, cuando no utiliza la parcela con carácter rotativo, da inicio a un proceso de barbecho prolongado. Se empieza a perfilar una transición de una agricultura de corto tiempo de cultivos estacionales, hacia un complejo silvicultural de largo tiempo que combina cosechas y bosque en regeneración. Entonces la intervención del indígena se limita a crear senderos para recoger los frutos de los árboles frutales que quedaron de la parcela y/o especies vegetales de diversa utilidad (medicinales).

Durante el barbecho se produce un reciclaje de nutrientes, ya que la materia orgánica añadida al suelo por la vegetación no solo aumenta el contenido de humus del suelo, sino que soporta una activa población biológica que devuelve una estructura física favorable.

Igualmente se presenta una reestructuración de la vegetación al término del estado sucecional temprano de unos 20-30 años, en el cual llegarían a diferenciarse estratos de más de $10 \mathrm{~m}$ de altura, fustes delgados y un sotobosque denso cubierto de helechos palmas y arbustos. En esos estados tempranos de la sucesión son predominantes especies pioneras como el guarumo (Cecropia spp), y balsa (Ochroma lagopus), combinados con ceibas (Ceiba pentandra) y otras especies dispersas. El sotobosque es denso, con presencia de helechos, platanillos (Heliconia spp) cañuelas, bejucos y arbustos.

Luego con el paso del tiempo a más de 30 años, los estratos superiores podrían alcanzar alturas superiores a los $35 \mathrm{~m}$ y diámetros superiores a $20 \mathrm{~cm}$, orientándose a ser un bosque primario. En este estado predomina la presencia de árboles dispersos de gran tamaño de las especies de las familias Moraceae, Ficus e Ingas principalmente. El sotobosque se torna menos denso con la presencia de helechos, arbustos y diferentes palmas.

De manera general los indígenas miskitu presentan una alta utilización de especies nativas, para enfrentar sus necesidades básicas, dado que los bosque tropicales contienen una biomasa aprovechable en más del 90\% para los usos de los nativos. Así mismos el uso que hacen de las especies silvestres es diversificado y guarda relación con los aspectos de su vida cultural. La recolección de vegetales, frutos, raíces, tallos, bejucos, y hojas constituye una actividad complementaria y subsidiaria para la dieta, la construcción, la artesanía, y la medicina tradicional. Por lo tanto la destrucción del bosque, o el cambio de uso del suelo, no cabe en la memoria colectiva de los 


\section{CULTURA INDÍGENA Y AFRODESCENDIENTE}

comunitarios miskitus, sino que siempre están pendientes del regreso de la vegetación y la recuperación de los suelos después de un período de agricultura.

\section{Mecanismo de trabajo de la parcela}

Durante el ciclo agrícola preparatorio del suelo hasta la cosecha los comunitarios se practican ejercicios de cooperación, ellos utilizan mecanismos de apoyo mutuo como el Pana Pana ${ }^{[6]}$ y el Taya Nani ${ }^{[7]}$. Estos mecanismos de cooperación se fundamentan más en las relaciones de parentesco o sea mediante el Mihta alki ${ }^{[8]}$ (mano vuelta, o te ayudo y tú me ayudas). Pero también es la forma de cómo se trasmiten los conocimientos de interacción con la naturaleza de generación en generación.

Una comunitaria miskitu explicó que ella va con sus padres y a veces con su hermano a ayudarles en todo el proceso de cultivar el suelo para adquirir conocimientos, que luego serán trasmitidos a sus hijos.

"mis padres me explican la diferencia entre el tipo del suelo y la relación de esta con el cultivo a sembrar, según textura y color él sabe qué tipo de suelo es mejor para tal cultivo... es un sabio".

Ella mencionó que su hermano también le enseñó el tipo de suelo apto para los bananos y plátanos (musáceas), no así para otros cultivos. En base a estas características que van definiendo en las parcelas y se pueden establecer de 3-7 cultivos, pero también utilizan pocas herramientas de trabajo, a lo sumo utilizan hachas y machete para preparar la parcela y la siembra se hace al espeque principalmente, o sea utilizar una vara con punta para el hoyado del suelo y depositar la semilla.

Considero que los sistemas productivos indígenas son la riqueza y el patrimonio de cada familia, pero también es un espacio único, producto de la experimentación e intercambio entre los pueblos, las semillas vienen de los viejos o se recuperan en visitas a parientes o amigos tras largas jornadas de camino. Por otro lado, la agricultura y la cría de animales domésticos no se tratan de un asunto meramente técnico o agronómico, sino que están fuertemente enraizados en aspectos culturales. El conocimiento de cada especie y de cada sistema es variado, no es uniforme y depende del grado de manejo cultural.

Entonces el sistema productivo comunitarios se basa en principios agroecológicos, se basa en las experiencias indígenas sobre la dimensión ecológica, pues analiza

[6] Pana Pana se interpreta como ayuda mutua entre comunitarios.

[7] Taya nani se interpreta como una ayuda mutua en familiares comunitaria.

[8] mihta alki es definido como acuerdos verbales mutuos entre miembros de una comunidad, en donde la base es la retribución mediante el trabajo recíproco en el menor tiempo posible. 
la apropiación y utilización del agro ecosistema por parte de las unidades familiares indígenas, su sabiduría, racionalidad y significados prácticos”.

\section{Cultivos principales y su distribución}

En relación a los suelos del área de estudio donde habitan las comunidades indígenas, de acuerdo a un informe de la FAO, (Taylor, 1959), la tierra es de origen aluvial, de color café y tiene un rango de $20-80 \mathrm{~cm}$ de profundidad y son suelos con buenas condiciones para la agricultura.

La textura de los suelos son de marga arenosa marga arcillosa y arcilla aluvión. Se dice que el drenaje va de bueno a mejor y se considera que los suelos son en general muy fértiles. Estas características son muy reconocidas por los comunitarios que lo identifican por el color, la profundidad de los colores, la textura y olor del suelo.

De igual manera, los sistemas agroalimentarios de los miskitus combinan dentro de las parcelas distintos cultivos dispersos y al parecer muy desorganizados, pero con una alta diversidad intra e inter especifica. Las especies que sobresalen se describen a continuación: musáceas (plátano, banano, filipito), yuca (Manihot esculenta), arroz (Oriyza sativa), frijol (Phaseolus vulgaris), tubérculos. Así mismo se destaca la pesca y la caza como actividades complementarias a la agricultura.
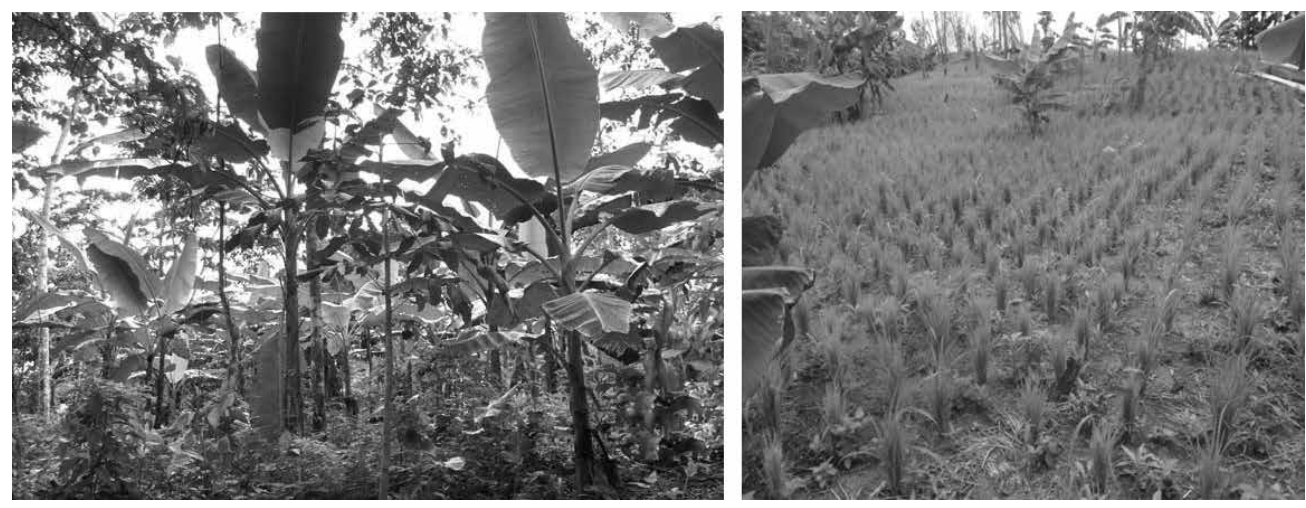

Figura No. 1.: Cultivos básicos de los sistemas productivos miskitus.

Las musáceas, los tubérculos, el arroz y los frijoles, representan la base de la dieta alimenticia, por su alta diversidad de preparación y consumo. Se consume durante casi todo el año por las familias. Cabe mencionar que el establecimiento y manejo agronómico de estos cultivos es de gran dominio por los comunitarios ya que es rustico. Son especies criollas y resistentes al volcamiento, y a los problemas de plagas.

Su manejo es muy seguro, se hace un deshierbe para la siembra y luego otra a los 40-6o días dependiendo de las especies y luego la cosecha. Pero también dependiendo 
del tipo de suelo y de las malezas se hacen deshierbes más seguidos. Cuando los cultivos están en etapa de floración y cosecha, generalmente es la mujer la que visita el sitio de siembra 2-4 veces por semana, quien aprovecha para hacer una pequeña limpia, corta con machete las malas hiervas alrededor de las plantas y para mantener presencia en la huerta y evitar robos de las cosechas. La visita al huerto se hace muy temprano por la mañana es desde las 6:00 am hasta las 11:00 am.

Los árboles frutales también forman parte del sistema productivo agroecológico comunitario, sin embargo se maneja aparte del huerto familiar. Estos árboles están relacionados directamente a los sitios de asentamientos de las comunidades dando la sensación de estar en un perfecto sistema agroforestal de economía de patio. Un ejemplo de esto es que en la comunidad de Tasbarraya cada casa tiene sembrado muchos árboles frutales (cítricos, aguacates, cocos, zapotes), plantas aromáticas (condimentos) y medicinales en sus alrededores.

Según los comunitarios, la distribución de los cultivos depende en gran parte del tamaño, la distancia y forma de la parcela. Son policultivos ordenados de diferentes formas, según el propio criterio de los comunitarios productores (conocimientos trasmitido por sus padres) y la necesidad de maximizar el espacio, ya que muchos mencionaron que es difícil para ellos limpiar áreas más grandes para cultivar.

En cuanto al papel de las mujeres en las actividades agrícolas, una mujer indígena miskitu explicó lo siguiente.

La mujer en la agricultura trabaja mucho[...] es la que se levanta muy temprano para preparar la comida, cuando termina la comida acompaña a su marido a la limpieza del terreno, pero antes en la noche conversa con el hombre sobre el lugar de siembra y toman decisión sobre el lugar, y al final es ella la que da el visto bueno... cuando se va tumbar arboles, ella siempre acompaña al marido y emite su opinión al respecto, a la hora de siembra igual cocina y prepara comida para el grupo y los reparte... en el caso de la siembra ayuda con cargar las cepas de bananos o la madera de yuca eso depende de lo que se va a sembrar [...] en la limpieza de la parcela, igual tiene una participación directa, con el control de maleza y el aporque de los cultivos.

Es notorio que las mujeres tienen una gran responsabilidad de trabajo para lograr la producción agrícola, se complementa con su marido y el resto de la familia para sacar la producción.

Generalmente los sitios de siembra están establecidos en zonas particularmente cercanas a las comunidades y de fácil acceso, normalmente en la vega (orillas) de los ríos que sirven como medios de transporte para sacar los productos. La distancia de la parcela su casa varia de 2-5 kilometros. 


\section{Árboles frutales}

En el sistema productivo comunitario se asemeja a los sistemas agroforestales por la combinación de una diversidad de árboles dentro de su área agrícola y en los alrededores de su casa. Los principales cultivos son naranjas, limones, fruta de pan, piña, cacao, coco, entre otros. Son arboles que le dan manejo constante durante la limpieza de su patio. Las frutas completan su alimentación a base de carbohidratos (arroz, frijoles, yuca, musáceas).
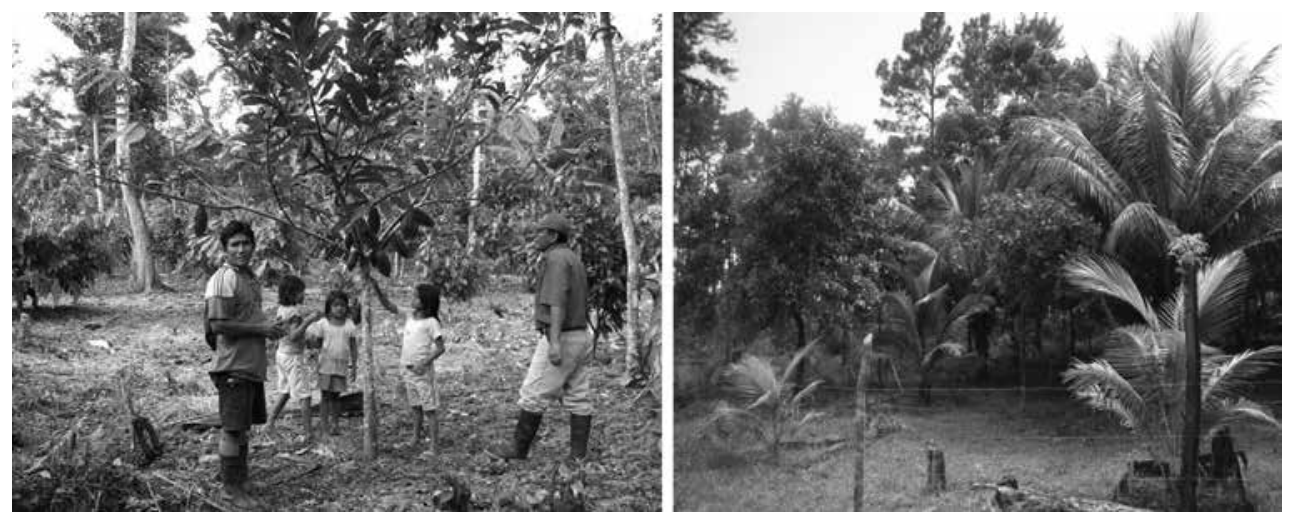

Figura No. 2. Sistema agroforestal de comunidades mestizas.

\section{Recolección de especies}

El concepto de recolección agrupa actividades extractivas tradicionales que aun siguen siendo desarrolladas por el pueblo miskitu en menor escala y frecuencia, como son la recolección de especies vegetales y animales, incluyendo la caza y la pesca.

\section{Recolección de especies vegetales}

Estas plantas son utilizadas para la construcción de casas, alimento, medicinas, rituales, artesanías y como leña. Las construcciones pueden incluir viviendas, cercos, botes (canoas) y remos. Por otro lado, para la alimentación humana se recolectan frutos, cogollos, y raíces. En las plantas medicinales se recolectan hojas, tallos flores, frutos y raíces provenientes de plantas con diferentes hábitos. Con fines de rituales también recolectan algunas plantas que expelen ciertos aromas, y para artesanías recogen fibras para amarres y cabuyas. Para la leña se recolectan tallos, ramas y arbustos de diferentes especies.

Algunos productos del bosque que recogen y que se usan como alimentos secundarios, son frutas silvestres, huevos de reptiles y de aves, y algunas especies de tortugas de ríos. 
Algunos productos silvestres vegetales son: nancite, manzana de mono, jocote de mono, granadilla de monte, cacao silvestre, pijibay, icacos, sapotes, el fruto de la palma ujum, entre otros.

\section{Recolección de especies animales}

La recolección de especies de animales en las actividades de casería y pesca, es una de las principales en la vida comunitaria. Estas proporcionan gran cantidad de proteínas a la familia. Se realiza principalmente sobre los ríos o quebradas de su territorio comunal. Tanto para la cacería como para la pesca, los comunitarios empleas una gran cantidad de tiempo.

\section{Pesca}

Los peces de mayor abundancia son: la mojarra (Aequides Spp), el barbudo (Pimelodus clarias), y la sardina (Astyanax Spp). La época de mayor pesca es en el verano que inicia en el mes de febrero y finaliza en el mes de mayo.

Los instrumentos de pesca varían de acuerdo a las especies y con la hora de captura. Por ejemplo los barbudos y las mojarras se pescan por la tarde con la bajada del sol y se utiliza cuerda de nylon, anzuelo y carnada (lombrices, masa de harina, sardinas), en cambio las sardinas se pescan con redes o telas finas. Esta última técnica es usada más por las mujeres en los riachuelos y quebradas con poca profundidad.

\section{Casería}

Para la casería es fundamental un buen perro y una escopeta o rifle (o.22). En algunos casos los indígenas conocedores de la relación planta - animal, imitan los cantos y gruñidos de los animales para atraerlos, pero también pueden identificar a los animales por sus huellas o por los alimentos que consumen.

Los principales animales de cacería son: la iguana (Iguana sp.), el venado cola blanca (Odocoileus virginiana), la guardatinaja (Pecari tajacu), el armadillo (Dasypus novemcinctus), el tapir (Tapirella sp), entre otros.

\section{Cría de animales domésticos}

Los principales animales de cría doméstico son los cerdos y aves, pues aportan al consumo como alimento. Siempre tienen de 2-3 perros que ayudan para la casería. Por otro lado un bajo número de comunitarios poseen algún ganado vacuno (vacas) que las tienen como banco de dinero y la comercializan cuando se les presenta algún problema familiar o la celebración de alguna fiesta. 
Los cerdos se mantienen sueltos para disminuir las labores de manejo, ya que asi el animal se rebusca su alimento. En algunos casos esta situación de los cerdos ocasiona problemas graves de enfermedades por la distribución de materia fecales alrededor de la casa y del tambo formado focos de infección. Los cerdos también causan daños a los cultivos (escarban los huertos) y son muy susceptibles a las enfermedades por el clima (alta precipitación).

Los cerdos se alimentan de muchas plantas gramíneas, y de los frutos y semillas caídos de los árboles frutales en los alrededores de la casa, principalmente en cosechas de naranjas, fruta de pan, sapotes y aguacates.

Las aves criadas por las comunidades indígenas son básicamente las gallinas. Son para el autoconsumo y generalmente viven sueltas consumiendo insectos, gramíneas y desechos de la cocina, creándose una relación ecológica entre estos dos. Se construyen gallineros para el refugio de las gallinas, debido a la presencia de zorros depredadores de aves. La postura de huevos se realiza en sitios preparados en la casa o en rastrojos cerca de estas.

\section{Aprovechamiento maderable del bosque}

En la práctica hay una variedad de formas de aprovechamiento del recurso forestal. Dentro de esta complejidad de formas, podemos agruparlas en dos grandes grupos y ambos sistemas se dan en los modelos de comunitarios indígenas y mestizos.

Aprovechamiento de autoconsumo: es una modalidad utilizada en comunidades indígenas para fines locales. La cantidad varía acorde a la disponibilidad de los recursos. El líder comunal explica que las cuotas asignadas por familia pueden ser de unos 1500 a 2000 pies tablares las veces que lo solicitan los comunitarios, pero la extracción deberá ser de su propia parcela.

No existe una ruta de decisiones colegiadas, el comunitario puede extraer los arboles que necesita para satisfacer alguna necesidad presente, tales como: la construcción de casas, muebles, artesanía, remos, canoas y otros artefactos. Peo los excedentes pueden ser vendidos fuera de la comunidad a fin de adquirir recursos económicos para satisfacer algunas necesidades del hogar.

Aprovechamiento para comercialización: al igual que ocurre con la venta de los productos agrícolas, los comerciantes madereros se aprovechan de la figura de los permisos comunales y encargan "una camionada de madera que puede equivaler aproximadamente de 5 a 7 mil pies tablares de madera. Entonces algunos comunitarios se juntan y recogen la cantidad solicitada y se extrae de sus lotes asignados. 
También existe la modalidad de comercialización de madera comunal, en donde la junta directiva de la comunidad elabora un plan de manejo y solicita un permiso de aprovechamiento ante las instancias correspondientes (INAFOR). La madera se extrae de las áreas de uso colectivo (comunal). Los beneficios generalmente se utilizan para solventar alguna necesidad de la comunidad, por ejemplo: la compra de materiales para la iglesia, la escuela, entre otras.

\section{No maderables del bosque}

Los recursos forestales no maderables que las familias aprovechan con frecuencia son las hojas de yarina (Phytelephas macrocarpa), y papta (Geonoma borngniartii), para la cobertura de las casas, también la uña de gato (Uncaria tomentosa), hombre grande (medicinal), y la miel de abejas. Estos recursos no siempre están en la unidad productiva, por lo que se extraen del boque comunal o en área de libre disponibilidad y acuerdos entre comunidades vecinas (uso colectivo).

\section{Conclusiones}

Los pueblos indígenas y sus medios de vida están fuertemente asociados a los recursos naturales del bosque, ríos, lagunas y a los ritmos "naturales" del medio ambiente, y aunque existe un proceso de frontera agrícola interna en las comunidades indígenas, ellos mantienen sus características de cazadores/pescadores/recolectores y desarrollan algunas actividades agropecuarias.

El sistema es un tanto diversificado e incluye cultivo de granos, tubérculos, musáceas, frutales, crianza de cerdos y en menor medida pequeños hatos de ganado vacuno. Estas actividades productivas son prácticamente orgánicas y la reducida presencia de ganado permite la regeneración natural del bosque en las parcelas dejadas en descanso.

Su sistema productivo utiliza la roza, tumba y quema para desarrollar su sistema productivo, no obstante la diferencia se basa en el período de barbecho del suelo. Practican un sistema de barbecho largo que dura de 5-10 años o más que permite la recuperación del bosque desde el proceso de sucesión primaria hasta la conformación de un bosques secundarios. Esto permite la recuperación del suelo y evita el cambio de uso del suelo. 


\section{Lista de referencia}

Alistar (2007). Diagnóstico del territorio Amassau de la comunidad de Awastingni. RAAN, Nicaragua.

Alcaldía Waspam. (2009). Plan de desarrollo Municipal 2008-2018. RAAN, Nicaragua.

Calderón, V. (2002). Análisis Multitemporal del Cambio de Uso de Suelo en base a Imágenes Satelitales y su Relación con las Patentes de Desmonte en el Área de los Municipios de Concepción y San Javier en los períodos 1996 - 1998 Y 1998 - 2000.

CONADETTI (2008). Informe de invasión de tierras por terceros en las Zonas de Tasbarraya. RAAN, Nicaragua.

FAO (2010). Estado de los bosques del mundo. Documento de Trabajo 1.Roma, Italia.

Grumber, G. (2007). La diversidad humana, identidades en un contexto Multicultural. URACCAN, NICARAGUA.

INAFOR (2010). Inventario Forestal Nacional. Manágua Nicarágua.

IDH (2005). Informe de desarrollo humano las regiones autónomas de la Costa Caribe nicaragüense.

MARENA (2011). Informe del estado Ambiental en Nicaragua.

Mordt, M. (2002). Sustento y sostenibilidad en la frontera agrícola.

NITLAPAN (2010). Estrategias de adaptación al medio del Huracán Félix. Los casos de Butku y Awas Tingni. 